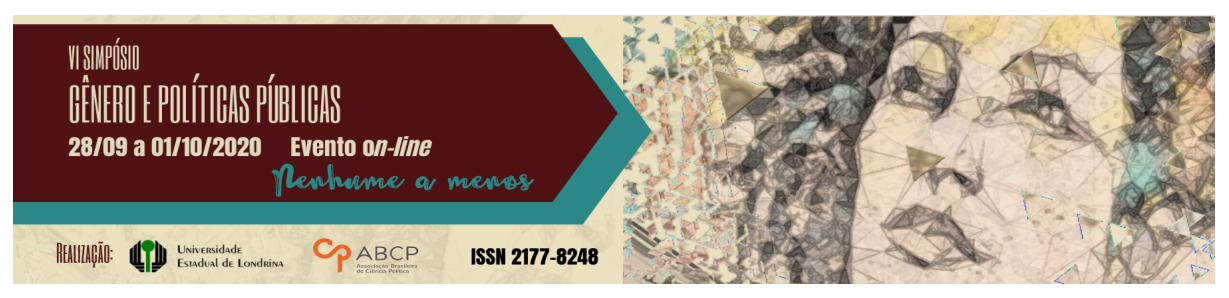

\title{
A discussão sobre políticas de licenças parentais no Brasil: Caminhos possíveis e desafios
}

\author{
Fernanda Sena Fernandes ${ }^{1}$; Janaína Xavier Nascimento²
}

\section{Resumo}

Este trabalho visa analisar as políticas de licenças maternidade e paternidade no Brasil, bem como a possível adoção de uma licença parental no país, usando como comparativo os modelos da Suécia, país pioneiro na adoção de tal política, e de países latino-americanos, como Cuba, Chile e Uruguai. A partir de revisão bibliográfica e análise de documentos bem como estudo de dados estatísticos, busca-se compreender de que forma a adoção de uma licença parental no Brasil seria benéfica para a diminuição das desigualdades de gênero. Conclui-se que apesar da resistência da implementação da medida por segmentos sociais alinhados a um discurso mais conservador, a mesma teria impactos positivos, vide os modelos de outros países analisados e seus resultados, proporcionando uma diminuição na divisão sexual do trabalho e progressivamente promovendo mudanças culturais para que as próximas gerações tenham condições de gênero mais equitativas.

Palavras-Chave: políticas públicas; gênero; licença parental

\section{A discussion about parental leave policies in Brazil: possible paths and challenges}

\begin{abstract}
${ }_{1}^{1}$ Acadêmica de Licenciatura em Ciências Sociais pela Universidade Federal de Santa Maria. E-mail: nandasefernandes@gmail.com

2 Professora adjunta no Departamento de Ciências Sociais da Universidade Federal de Santa Maria; Doutora em Sociologia Política pela UFSC/Universität Berlin

GT 18 - Políticas públicas de gênero no Brasil do século XXI: avanços e desafios
\end{abstract}


This research seeks to analyze the maternity and paternity leave policies in Brazil, as well as the possible adoption of parental leave, or family leave, in the country, using as a comparison the models adopted by Sweden, a pioneer country in the adoption of these policies, and by other Latin American countries like Cuba, Chile and Uruguay. Starting with a bibliographical review and a series of documental analysis, as well as the study of statistical data, we seek to understand how the adoption of parental leave in Brazil could be beneficial for the reduction of the gender gap. The analysis led to the conclusion that, despite the resistance towards the implementation of these measures by a more conservative social segment, the adoption of these policies would have a positive impact in the country, just as happened in the other countries that implemented them, providing a decrease ingender gaps regarding employment, and progressively promoting cultural changes so that future generations may have more equitable gender conditions.

Keywords: public policy; gender; parental leave.

\section{Introdução}

Atualmente no Brasil vigoram políticas de licenças maternidade e paternidade que escancaram os papéis de gênero no país. Com 120 dias de licença maternidade e apenas 5 dias de licença paternidade, as mulheres ainda são destinadas prioritariamente ao espaço privado, desempenhando $92,1 \%$ das tarefas domésticas frente a $78,6 \%$ dos homens ${ }^{3}$. Tendo em conta que as políticas públicas são reflexo da sociedade que as produz, e que as mesmas tanto podem ser feitas pelo Estado como podem ser adquiridas após pressão popular de movimentos sociais, o que percebemos é que as políticas de licenças parentais no Brasil institucionalizam as diferenças entre trabalho reprodutivo/feminino e trabalho produtivo/masculino.

Observando estas discrepâncias, surge a indagação: qual o motivo das políticas de licenças no Brasil serem tão desiguais? Tal pergunta suscitou esta pesquisa que busca compreender de que forma trilhamos este caminho, onde estamos e para onde podemos ir. Assim, o artigo inicia conceitualizando as políticas públicas, sua finalidade e 
intersecção com a categoria gênero, de forma a compreender porque ao estudarmos o regime de licenças parentais não há como dissociar um conceito do outro. A seguir traça-se um breve panorama das políticas para a maternidade no Brasil, constatando-se que as mesmas assumem, num primeiro momento, um caráter instrumentalista, com a regulamentação indo de encontro a papéis sociais de gênero desejados pela sociedade brasileira da metade do século $X X$, e mais emancipadoras a partir da abertura democrática no fim dos anos 1980, com as mulheres adquirindo diversos direitos através da luta dos movimentos feministas e de mulheres, sem, no entanto, conseguirem mudar o status quo em relação a participação masculina no âmbito doméstico.

O artigo também analisa o modelo de licenças parentais sueco, que hoje já dispõe de 480 dias a serem compartilhados com os pais, além de analisar os casos latino-americanos de Cuba, Chile e Uruguai, que também adotam o modelo de licenças parentais. Além disso, busca-se examinar as tentativas, ao longo de 32 anos de Constituição, de regulamentação da licença paternidade e/ou propostas de licença parental. Conclui-se este trabalho constatando que há resistência de alguns segmentos sociais em relação à adoção de uma política de licenças mais amplas para os pais, especialmente dado o contexto de avanço conservador. No entanto, apesar deste obscurantismo, nascem nichos de pais que defendem uma paternidade mais ativa, o que indica que, caso adotada, a licença parental com mais dias disponíveis aos pais poderia contribuir não apenas para a igualdade entre homens e mulheres, mas também na (des)construção de masculinidades mais saudáveis, o que impactaria as gerações futuras promovendo novos arranjos de gênero.

Gênero e políticas públicas: breves discussões conceituais 
As políticas públicas regulam atividades do Estado no que concerne ao bem-estar da população, como educação, saúde e seguridade social. Nascidas durante o século XIX, as políticas públicas eram, inicialmente, políticas sociais, coordenadas por um movimento assistencialista formado por Igrejas e grupos de mulheres da alta sociedade, tendo como foco a mera assistência e não a superação da pobreza em si.

Com a crescente industrialização e a organização da classe trabalhadora em sindicatos, reivindicações por direitos passaram a ser pauta do movimento operário, o que culminou em diversas revoltas e greves que resultaram em uma progressiva incorporação pelo Estado de medidas que assegurassem esses direitos. Assim, tais políticas eram utilizadas como ferramenta de pacificação dos movimentos de trabalhadores ao mesmo tempo que determinava padrões que, em um contexto fortemente nacionalista, passavam pela intervenção na vida privada no intuito de hegemonizar comportamentos familiares. Neste contexto as políticas para a maternidade surgiram tendo como principal alvo não as mulheres, mas as crianças, vistas como futuro da nação, mas que não podiam ser acessadas sem passar por suas mães. Percebe-se então, que falar de políticas sociais também é compreender uma forte relação de gênero, que permearam as mesmas num sentido instrumentalista.

Estas políticas foram adotadas de forma mais enfática após a Segunda Guerra Mundial, dado o contexto econômico posto, especialmente a entrada massiva das mulheres das classes médias no mercado de trabalho. De acordo com Marshall (1967, p. 61), estas políticas se consolidam como ferramentas do Estado utilizadas para ampliação do ideal de cidadania, objetivando não a erradicação das diferenças de classe, mas sim condições de participação em uma sociedade capitalista.

No entanto, como aponta Walby (2004), Marshall acabou por não observar as questões de gênero, latentes nos espaços privados e que acabavam por não oferecer ampla cidadania para as mulheres, já que 
estas políticas eram elaboradas pelos homens, privilegiados pelos trabalhos de cuidado, fazendo com que o trabalho reprodutivo sequer fosse visto como uma forma de trabalho (BIROLI, 2018, p. 82). Assim, percebendo que por gênero entendemos a construção "social das ideias sobre os papéis próprios aos homens e às mulheres" (SCOTT, 2012, p. 7), observar as políticas públicas para a maternidade é compreender que as mulheres não só desempenham o trabalho reprodutivo, mas também o produtivo, gerando-se aí um forte paradoxo em uma sociedade capitalista que se por um lado exige o desempenho do trabalho produtivo, por outro não oferece estruturas para que o trabalho reprodutivo não seja fator limitante para as mulheres.

O tema teve tanta força no início do século XX que foi pauta da Convenção $\mathrm{n}^{\circ} 3$ da Organização Internacional do Trabalho (OIT) em 1919. Esta convenção foi um marco importante nos direitos das mulheres trabalhadoras, e dentre suas resoluções estavam a adoção pelos países signatários da licença de seis semanas anteriores e seis posteriores ao parto, garantia de um abono salarial no período de licença pelo Estado, além de benefícios médicos pagos, proibição da demissão das gestantes e pausas durante a jornada de trabalho para amamentação (REA, 2002, p. 392). O Brasil, contudo, só viria a acatar as resoluções de forma integral em 1943, ainda sim permanecendo um dos países pioneiros em relação aos direitos trabalhistas das mulheres mães.

\section{Políticas públicas para a maternidade no Brasil}

No Brasil a questão da cidadania feminina, assim como a de outros grupos minoritários, é complexa e permeada por relações de poder não apenas de gênero, mas também de classe e raça. Com uma estrutura oligárquica, a história do Brasil é marcada pela manutenção dos privilégios da elite e de uma desigualdade social profunda que por muito tempo inviabilizou o reconhecimento de direitos de uma minoria social. Esta característica se mostra através das esparsas tentativas de implementação de políticas sociais no Brasil entre o fim do século XIX e 
o início do XX, especialmente no período da República Velha, que além de serem escassos, ainda eram definidos por traços assistencialistas e higienistas.

No que concerne às mulheres, as políticas anteriores às adotadas por Getúlio Vargas eram parcas e visavam o combate da mortalidade infantil. Em um contexto onde a medicalização e os ideais higienistas explodiam no país, encabeçados por figuras como Oswaldo Cruz, a categoria médica passou a pleitear uma intervenção do Estado, alegando que "o homem brasileiro ainda não tinha instrução e noção de responsabilidade que lhe permitisse andar sozinho sem as muletas do Estado" (MARTINS, 2010, p. 110). Desta forma algumas políticas foram adotadas, como a instauração em 1922, pelo governo Arthur Bernardes, do Departamento Nacional de Saúde Pública, que tinha dentre uma de suas metas o combate a mortalidade infantil e materna. As políticas adotadas, portanto, não tinham como foco principal a emancipação feminina ou mesmo a garantia dos direitos das mulheres, mas sim sua instrumentalização pelo Estado enquanto mães e cuidadoras.

Políticas mais concretas só foram adotadas a partir da Constituição de 1934, onde o voto feminino passou a ser um direito garantido, e de forma mais ampla com a Consolidação das Leis Trabalhistas em 1943, durante o período Vargas. Estas leis trabalhistas correspondiam às recomendações da Convenção $n^{\circ} 3$, e visavam o desenvolvimento econômico porém sem promover grandes mudanças sociais que de fato pudessem emancipar as mulheres (BESSE, 1999, p. 5).

Mudanças de fato pautadas pelas mulheres só ocorreriam durante a abertura política, com a Constituição de 1988, que teve participação ativa dos movimentos feministas e de mulheres em sua elaboração durante a constituinte. Com a Carta das Mulheres, conquistaram-se importantes avanços como a extensão da licença maternidade para 120 dias, a garantia do vínculo empregatício da confirmação da gravidez até o $5^{\circ}$ mês após o parto, excluindo-se poucos pontos do documento, como as solicitações de aumento da licença 
paternidade e de uma reforma agrária como direito das mulheres do campo. Ainda que estas políticas tivessem um caráter mais emancipatório, por outro lado a sociedade brasileira não modificava as profundas diferenças de gênero que decorriam no lar, permanecendo as mulheres como principais cuidadoras dos filhos, perpetuando a divisão sexual do trabalho no seio da família.

\section{Licença maternidade e paternidade e a divisão sexual do trabalho}

Por divisão sexual do trabalho podemos compreender "a destinação prioritária dos homens à esfera produtiva e das mulheres à esfera reprodutiva" (KERGOAT, 2003, p. 55), o que se comprova através dos dados do IBGE de 2018, que apontam que as mulheres desempenham até $73 \%$ a mais de horas de trabalho doméstico, dos quais o cuidado com os filhos compreende boa parte deste tempo. Além disto, elas também estão mais vulneráveis quanto à estabilidade no mercado de trabalho: segundo dados do IPEA de 2016, 52\% das mulheres se encontram em trabalhos pagos, contrastando com $77 \%$ dos homens. Entretanto, a pesquisa não aponta qual o tipo de trabalho pago desempenhado, o que pode ser um dado relevante, já que muitas acabam optando por trabalhos autônomos ou informais que ofereçam horários flexíveis de forma a conciliar a maternidade, abrindo mão da garantia de direitos, estabilidade ou mesmo de salários dignos. Mesmo quando estas conseguem se inserir no mercado formal, sofrem uma enorme pressão social para conseguirem ajustar trabalho reprodutivo e produtivo, muitas vezes não conseguindo dispor de tempo para essa dupla jornada e tendo de contar com uma rede de apoio.

Hoje, a licença maternidade garantida como cláusula pétrea da Constituição é de 120 dias para as mães, sejam as mesmas biológicas ou adotantes, contrastando com 5 dias de licença para o pai. Os funcionários públicos federais contam com tempo maior: 180 dias para 
as mães e 20 dias para os pais ${ }^{4}$ tempo este que se assemelha aos trabalhadores de empresas cadastradas no programa "Empresa Cidadã" (Lei 11.770/2008), que oferece isenções fiscais aos empresários adeptos em troca de melhores condições de trabalho e bem-estar para seus empregados. Esta licença, contudo, não é compulsória, sendo optativa para os funcionários. Além disto, poucos dados são encontrados sobre o impacto do programa no aumento das licenças, tornando difícil uma análise mais cuidadosa sobre sua adesão.

Assim, as mulheres são institucionalmente responsabilizadas pelo trabalho de cuidado das crianças. Por mais que aspectos biológicos tais como a amamentação devam ser levados em consideração em relação a concessão de tempo da licença maternidade, nada impede que os homens tenham mais tempo de licença e desta forma contribuam de forma mais efetiva nos cuidados com os filhos.

Obviamente deve-se considerar a própria questão da masculinidade e da construção da paternidade para compreender os motivos pelos quais ainda há tais discrepâncias nos tempos de licenças. Assim, a própria questão de gênero se coloca como "relações sociais na qual as capacidades reprodutivas dos corpos humanos são postas na história, e na qual todos os corpos, férteis ou não, são definidos por sua colocação na arena reprodutiva" (CONNELL, 2016, p. 60).

Esta questão é central, já que como aponta Weber (2004, p. 47), o trabalho está fortemente atrelado, em um sistema capitalista, à virtude, ao dever, o que corrobora para uma relação intrínseca entre masculinidade e capacidade de provimento. Assim, “a posição de provedor é ainda por eles reivindicada como se fosse uma prerrogativa, um direito, antes mesmo que um dever. Ser provedor da família para eles é algo importante, verdadeiro motivo de orgulho." (OLIVEIRA, 2004, p. 205)

4 Estes 20 dias correspondem a 5 dias garantidos por lei e mais extensão de 15 dias, concedida pelos órgãos públicos 
Diante de tudo isso, podemos nos perguntar: é possível que no Brasil se adote um modelo de licença parental tal qual países como Suécia, Finlândia ou, em uma maior aproximação geográfica e cultural, Chile e Uruguai?

\section{As políticas de Licença Parental: A Suécia e os países latino americanos}

Como já frisado, há de se considerar que as questões de gênero não devem ser lidas como advindas somente de aspectos biológicos, mas também há margem para erros decisivos quando tratamos as expressões de gênero unicamente como produto de socialização, afinal, há ali uma corporificação, que une aspectos biológicos e sociais (CONNELL, 2015, p. 91). A maternidade nos apresenta isso de forma clara, pois não somente temos imbricado ali a construção social sobre o que é ser mãe, mas também um corpo que gesta, pare, amamenta. Isso pode ser ilustrado através das experiências parentais de pessoas trans, onde pais podem parir e amamentar e mães acompanham o processo de forma externa. Portanto, assegurar um período de licença maternidade que garanta a recuperação do corpo após o parto e a amamentação do bebê é estritamente necessário.

No entanto, os aspectos biológicos prevalecem, não levando em consideração que homens têm a mesma capacidade de cuidados que as mulheres. Ramires (1997) realiza cuidadosa pesquisa com pais sobre suas percepções da paternidade, e revela que há nos homens um verdadeiro desejo de cuidar dos filhos, mas não se sentindo validados para tal. Em um dos relatos o pai narra que "uma das razões que eu me separei é que minha ex-mulher... ela queria concentrar tudo nela, inclusive a educação do L. Isso... pô, eu queria participar também, né, em tudo, principalmente na educação do L." (p. 92). Este aspecto se repete em muitas das narrativas trazidas, além do fato de que mesmo quando permitidos, estes pais não se sentem protagonistas deste cuidado, sempre acreditando que são coadjuvantes das mães. Isto 
promove um afastamento ou mesmo um sentimento de inadequação em relação a uma estrutura social.

Estas questões influenciam diretamente na construção das políticas de licenças parentais, afinal, com maioria nos cargos políticos, são os homens que elaboram e aprovam tais medidas. Assim, o ciclo necessário para que mudanças sociais sejam promovidas pelo estado, através da implementação de políticas públicas reivindicadas por grupos específicos e que ao longo do tempo se desdobrem em mudanças culturais, acaba sendo interrompido quando ou por um lado estes grupos não são ouvidos, ou por outro não se organizam a fim de terem suas agendas atendidas. Desta forma, não é possível mudar estruturas de poder sem movimentos que pressionem mudanças culturais (MOUFFE, 2013, p. 14).

Um exemplo de como as políticas públicas têm potencial de mudança cultural a longo prazo, é a Suécia. As políticas públicas voltadas para as mulheres na Suécia iniciaram-se após a quebra da bolsa em 1929, onde o emprego de mão-de-obra feminina fez-se necessário para que o país não afundasse economicamente. A entrada massiva de mulheres no mercado de trabalho, especialmente pós-Segunda Guerra, em um país com índices demográficos tímidos, reduziu drasticamente os níveis de natalidade, mesmo que o Estado fornecesse ampla oferta de vagas em creches, o que levou o governo social-democrata a pensar em novas formas de estímulo à natalidade sem, contudo, prejudicar a economia do país que necessitava do trabalho feminino. Assim, surge em 1974 a política de licença parental, um período a ser compartilhado entre os pais logo após o nascimento da criança.

A licença, a princípio a ser usufruída de forma alternada, pode ser usufruída em período integral, meio período ou com os pais trabalhando um quarto do tempo total da jornada laboral. A depender do regime adotado, os pais recebem abono de acordo com seus ganhos e, caso desempregados antes do nascimento, um valor fixo durante o período de licença (FARIA, 2002, p. 78). Assim, os pais que tiram a licença de forma integral recebem abono de acordo com seu salário 
anterior ao período de licença, os que optam por jornada de meio período a metade do valor e assim por diante. Além disso, implementou-se a licença compulsória para os pais, que desde 1995 não permite que os mesmos remanejem o tempo para as mães, aumentando a pressão do Estado para que os homens cumpram com sua parte nas tarefas de cuidado. Desta forma, os pais que não usufruíssem de seu período compulsório, perderiam o direito ao período extra. Assim, somados, os tempo compulsório e extra entre pai e mãe contabilizam 480 dias de licença (MATOS; OLIVEIRA, NATIVIDADE, 2016, p. 350), sendo destes, 90 dias exclusivos e obrigatórios de cada um dos pais, um tempo considerável e que garante não apenas um desenvolvimento saudável no primeiro ano da criança, mas uma divisão dos trabalhos reprodutivos.

Ainda que o modelo sueco seja eficaz, com os números progredindo e uma relativa mudança cultural promovida ${ }^{5}$, seria irresponsável pensar na aplicação de tal modelo no Brasil, em razão das condições históricas, políticas e sociais adversas, a começar pelos índices demográficos e pelo fato de sermos um país colonizado ao sul global'. Assim, um comparativo com países da América Latina torna-se mais realista e nos fornece reflexões mais assertivas sobre o tema. Hoje, no contexto latino americano, apenas três países têm licença parental: Cuba, o pioneiro, em 2003, Chile em 2011 e Uruguai em 2013.

Em Cuba o sistema de licenças se divide entre licença maternidade (pré-natal de seis semanas e pós-parto, de doze semanas) e o período de licença parental, que abrange não apenas os pais, mas se estende também aos avós. Ao finalizar a licença maternidade, inicia-se

5 Em 2002, cerca de 71\% dos pais suecos adotavam o período máximo de licença, segundo dados do levantamento de países nórdicos (http://www.divaportal.org/smash/record.jsf?pid=diva2\%3A701827\&dswid=-7555). Hoje, sites de notícias contabilizam $90 \%$ de adesão, mas não conseguimos dados oficiais que comprovem tal estatística.

6 Por sul global compreendemos países que não fazem parte do "grupo de países capitalistas ricos da Europa ocidental e da América do Norte, antigamente centros de impérios e hoje o "coração" da economia global" (CONNELL, 2016,p. 50), ou seja, o Sul Global corresponde aos países colonizados por tais potências econômicas em diversos momentos da História, seja direta ou indiretamente. 
a licença parental, que se prolonga até que a criança atinja um ano de idade. Durante este período a mãe pode optar por voltar ao trabalho, recebendo seu salário mais a remuneração social que corresponde a $60 \%$ de seus ganhos, ou delegar o cuidado da criança ao pai ou aos avós, que receberão o benefício (MELO, 2019, p. 37). Há ainda, a possibilidade de extensão da licença após a criança alcançar um ano de idade e ainda precisar de cuidados da família, em até três meses, sendo este benefício pago pelo empregador e não pelo Estado. Não foram encontrados, no entanto, números que mostram o impacto de tal política no país, nem o número de pais que aderiram ao benefício.

No Chile, a licença parental surgiu 17 anos após a licença paternidade, estabelecida em 1994 e com direito a 5 dias de afastamento pelo pai. Em 2011 foi instituída a licença parental, que conta com a possibilidade de adesão em período integral de doze semanas, ou meio período, se estendendo para 18 semanas. Esta licença é compulsória para a mãe em 6 semanas e optativa ao pai após este período e deve ser concedida pela mãe, ou seja, se a mãe assim quiser, pode "doar" dias ao pai. Durante o período é pago aos pais $100 \%$ do valor do teto do abono, independente da renda anterior. Além disso, há viabilidade de ampliação do tempo de licença em casos de bebês prematuros ou múltiplos. No Chile, desde sua implantação até 2014, das 274.264 licenças concedidas, somente 718 foram divididas com o pai (ANDRADE, 2018, p. 88). Em dados mais recentes, de janeiro de 2020, 7564 licenças parentais foram concedidas, sem, entretanto, a superintendência de seguridade social assinalar quantas destas foram divididas com os pais ${ }^{7}$. O mesmo ocorre com dados dos anos posteriores, sendo desta forma, difícil traçar um panorama do impacto de tal política nas questões de gênero do país.

O Uruguai é outro país da América latina que adotou a licença parental logo após a instituição da licença paternidade universal, já que a mesma foi adotada em 1990 para funcionários públicos e somente em

7 Dados disponíveis em: https://www.suseso.cl/606/w3-propertyvalue10294.html\#estadisticas 
2008 para o setor privado. Em 2013 o país aderiu ao sistema de licença parental que se estrutura no formato de "meio período restrita a trabalhadores do setor privado, a ser utilizado pelo pai ou mãe, não concomitantemente, após o fim da licença maternidade, até que o bebê complete 6 meses" (ANDRADE, 2018, p. 102). Este período, assim como no Chile, é optativo ao pai, tendo de partir da mãe a concessão dos dias de licença. No Uruguai, a adesão à licença também é tímida: de 2013 a 2017, somente 512 pais desfrutaram do benefício, com relativa progressão de ano a ano, sendo no primeiro apenas 57 pais e no último 183 (URUGUAY, 2017, p. 18).

O que podemos perceber é que apesar do modelo sueco ser mais avançado, também pelo fato de já estar em vigor há 46 anos, as políticas de licenças parentais do Chile e do Uruguai já mostram pequenos avanços no curto período de tempo em que estão em vigência. Há ainda muito a se trabalhar, e o que podemos destacar como eficiente no modelo sueco é a imposição da licença compulsória para os pais, o que acaba criando condições materiais para que a divisão das tarefas domésticas se realize, provocando mudanças culturais progressivas em relação à equidade de gênero. Nos países latino americanos só poderemos analisar o real impacto destas políticas nos próximos anos, através dos dados fornecidos sobre o número de benefícios concedidos.

\section{A Licença Parental em discussão no Brasil}

Como já exposto, o sistema de licenças parentais no Brasil é baseado em uma enorme disparidade, e sua equiparação vem sendo colocada em discussão há algum tempo, embora este debate não chegue à maior parcela da população e fique confinada em círculos políticos de esquerda e nos movimentos feminista e de mulheres.

Em 1985, na Carta das Mulheres, reivindicava-se “Licença ao pai nos períodos natal e pós-natal" além de exigir condições materiais para o exercício pleno da paternidade e igualdade entre homens e mulheres nos cuidados com os filhos. Estes itens, no entanto, foram excluídos do 
texto final da Constituição, num movimento de concessão pelas lideranças feministas no intuito de aprovar o máximo possível de itens da carta (PINTO, 2003, p. 76). Assim, apesar de garantir a extensão da licença maternidade para 120 dias, a mobilização dos movimentos feminista e de mulheres não conseguiu modificar as condições necessárias para mudanças do papel do pai na sociedade brasileira.

Exemplo de como a questão da paternidade ativa ainda é negligenciada na legislação brasileira é o fato de que apesar de não igualar o período das licenças, a Constituição de 1988 assinala no artigo $9^{\circ}$ que "Até que a lei venha a disciplinar o disposto no art. $7^{\circ}$, XIX, da Constituição, o prazo da licença-paternidade a que se refere o inciso é de cinco dias.". Esta regulamentação veio apenas em 2016, através de decisão do Supremo Tribunal Federal, com um atraso de 28 anos e ainda não atendendo as demandas sociais que se apresentam.

Ao longo deste tempo algumas propostas de lei foram aventadas. A mais bem sucedida foi o programa Empresa Cidadã, sancionado em 2008, que oferece benefícios fiscais às empresas que concederem extensão de licença a pais e mães. Os pais ganham 15 dias a mais, além de terem de participar de cursos sobre paternidade responsável. No entanto, é opcional ao funcionário este período extra, tendo o mesmo que entrar com o pedido de ampliação da licença até dois dias depois do nascimento do filho. Uma das empresas aderentes, o banco Santander, que conta com 53.848 colaboradores, já registra adesão de 93\% dos homens à licença paternidade estendida, além de ofertar um programa de atenção aos cuidados pré-natais, tanto a mulheres quanto a homens que integram a empresa, obtendo 2.693 adesões ao curso (2019, p. 35). Entretanto o Empresa Cidadã só atinge cerca de $18 \%$ das empresas brasileiras, o que acaba por não garantir licença paternidade de 20 dias de forma universal.

Outros projetos de lei foram levados ao congresso sem sucesso. É o caso da Proposta de Emenda Constitucional 16/2017, redigida pela deputada Vanessa Grazziotin (PCdoB) e assinada por uma frente ampla de parlamentares de diversos espectros políticos, que prevê a divisão 
dos 120 dias de licença maternidade entre pai e mãe. Esta proposta, no entanto, foi arquivada no final de 2018 e provavelmente não passaria, dado o fato de que os 120 dias são exclusivos da mãe, o que acaba por ferir a Constituição.

Já a proposta de Lei 151/2017, de autoria da Senadora Rose de Freitas (MDB) aventa a extensão da licença maternidade para 180 dias, com a possibilidade de divisão dos dias entre os pais, sendo concedido ao pai 60 dias. Além disso, a proposta prevê o aumento da licença em casos de crianças com necessidades especiais para 360 dias, também com a divisão do tempo entre os pais. Esta proposta tramita atualmente no senado, não sendo, contudo, prioridade, já que sua votação vem se arrastando desde 2017.

Há ainda outras propostas que visam ou a implementação da licença parental, ou a extensão da licença paternidade. Ao estudarmos estas proposições encaminhadas ao congresso, contabilizam-se 36 propostas relacionadas ao tema, desde 1989. Ao ler cada uma delas percebemos um emaranhado de burocracias que acaba fazendo com que as mesmas caiam no esquecimento. O que chama mais atenção é a PL 3539/2008, que tem nada menos que 5 PLs diferentes acrescidas à ela, desde as que solicitam aumento de até 90 dias de licença paternidade (PL 3831/2012), às que garantem divisão do tempo de licença (PL 1099/2015). Destas, apenas algumas foram aprovadas, como a Lei da Empresa Cidadã, leis que garantem o usufruto das licenças para pais adotantes (PL 3431/2011; PEC 494/2006) e a lei que transfere os dias de licença maternidade da mãe para o pai em caso de falecimento da mãe (PL 6753/2010).

Recentemente a Ministra da Mulher, da Família e dos Direitos Humanos, Damares Alves, defendeu a extensão da licença maternidade remunerada para um ano, e a extensão da licença paternidade para 30 dias. Apesar de comemorada por alguns, a medida reforça os papéis de gênero, tornando mulheres vulneráveis a casos de discriminação de gênero no mercado de trabalho. No entanto, com a pressão do lobby empresarial, a ministra voltou atrás e a proposta sequer saiu do papel. 
Todos estes casos têm em comum o fator de resistência de setores sociais a mudanças que equiparem o tempo de cuidado dos filhos entre homens e mulheres. Algumas hipóteses podem ser levantadas. A primeira delas é o fato de que $87 \%$ dos parlamentares brasileiros são homens, com idade média de 56 anos, de acordo com a atual composição das cadeiras. Isto se dá pelo fato de que "a divisão sexual do trabalho doméstico incide nas possibilidades de participação política das mulheres porque corresponde à alocação desigual de recursos fundamentais para essa participação, em especial o tempo livre e a renda" (BIROLI, 2018, p. 23) e tem como consequência o poder de mudança colocado nas mãos de um grupo que, privilegiado pelo suporte doméstico que as mulheres oferecem ao fazerem o trabalho reprodutivo, não vêem como vantajosa a mudança do status quo.

A segunda possibilidade que pode ser aventada para tal objeção é o fator religioso. De acordo com o censo de 2010 do IBGE, 86,6\% da população brasileira declara-se cristã, dentre os quais, $29 \%$, segundo pesquisa do Datafolha de 2017, consideram-se evangélicos. Outro dado importante é o crescimento de 53,9\% do número de evangélicos especialmente nas periferias das 12 maiores regiões metropolitanas do Brasil $^{8}$. Estes números mostram uma ascensão nos últimos tempos de correntes neopentecostais, que tem como uma de suas características posicionamentos conservadores. Baseando-se em preceitos bíblicos que colocam a mulher na função de procriadora, dona do lar, e usando da chamada Teologia da Prosperidade para reforçar o papel do homem enquanto provedor, este segmento é representado por 90 deputados e senadores no congresso ${ }^{9}$, além de ter ampla influência em boa parte da população, especialmente nas classes mais baixas, através de inserções em programas de televisão, multiplicação de templos nas cidades etc. Estas características que tendem a fortalecer os papéis de gênero podem

\footnotetext{
8 Disponível em: https://www.cartamaior.com.br/?/Editoria/Sociedade-eCultura/O-fenomeno-evangelico-em-numeros/52/44150

9 Dísponível em: https://congressoemfoco.uol.com.br/legislativo/renovada-bancadaevangelica-chega-com-mais-forca-no-proximo-congresso/
} 
ser traduzidos nas falas da Ministra Damares, assim como em movimentos fundamentalistas que se dizem anti-feministas.

Por outro lado, mesmo com a obstinação em relação à mudanças por parte da sociedade brasileira mais conservadora, têm havido um movimento de pais que buscam uma paternidade mais participativa. Com podcasts, canais de youtube e blogs, uma paternidade mais ativa vem sendo reivindicada por um grupo de homens, geralmente de classe média e com escolaridade alta, que debatem sobre seus papéis na criação dos filhos, desconstroem alguns aspectos de uma masculinidade mais tradicional e refletem sobre possíveis mudanças nas relações de gênero no Brasil. Este movimento, ainda que tímido, pode representar uma mudança cultural lenta que vem ocorrendo no país, ainda que dentro de grupos muito específicos. No entanto, ainda não há uma organização enquanto movimento social destes pais, que poderia garantir-lhes uma “expressão simbólica, cuja efetividade social pode demonstrar-lhe reiteradamente que ele encontra reconhecimento universal" (HONNETH, 2009, p. 197).

\section{Considerações Finais}

Em um país com uma constituição histórica onde os grupos sociais são intrinsecamente hierarquizados, a conquista de direitos das minorias sempre trilhou caminhos repletos de entraves, com disputas de poder acirradas e luta por reconhecimento de diversos movimentos sociais. Com as mulheres não foi diferente, já que mesmo em momentos de conquista de direitos, os mesmos acabavam sendo utilizados de formas sutis como novos mecanismos de instrumentalização dos corpos e comportamentos femininos, transformados em políticas públicas que aparentemente protegiam os direitos das mulheres trabalhadoras, mas que no fim das contas acabavam por reforçar os papéis de gênero no âmbito doméstico. Assim, o sistema de licenças perpetuou-se, mesmo após a Constituição Cidadã que teve participação ativa dos movimentos feminista e de mulheres, como segregador em relação aos cuidados dos 
filhos, mostrando que a maternidade ainda figura como um obstáculo difícil no caminho de equidade de gênero, já que é constituído de fortes apelos morais que se construíram ao longo do tempo, especialmente a partir de um modelo burguês que potencializava o antagonismo público-masculino/privado-feminino.

Percebe-se, desta maneira, que as políticas públicas possuem tanto um caráter transformador, quando adotadas de forma a modificar práticas sociais, seja de "cima para baixo" com implementação pelo Estado ou pela conquista através das reivindicações dos movimentos sociais, ou uma face reguladora, que trabalha para manter o status quo, reforçando hierarquias sociais. Isto é perceptível quando comparamos a postura adotada em relação aos sistemas de licenças parentais nos países aqui listados. Enquanto na Suécia a implementação de uma licença que contemple pais e mães partiu do Estado a fim de combater as baixas taxas de natalidade do país sem, contudo, intervir na economia que depende da mão-de-obra tanto de mulheres quanto de homens, na América Latina, o movimento parece ser o oposto, com a efetivação tardia de uma licença paternidade a partir da exigência de movimentos feministas e de mulheres, que por motivos distintos no Uruguai e no Chile transformaram-se em licenças parentais. No caso do primeiro, consequência da "onda rosa" que levou José Mujica ao poder, com projetos sociais que iam de encontro a uma maior garantia de igualdade na sociedade uruguaia. Já no Chile, a adoção da licença parental se deu durante o primeiro mandato de Sebastian Piñera, por motivos econômicos, visto que a licença paternidade em função de doença dos filhos acabou se mostrando desvantajosa para os empregadores, sendo a licença parental melhor regulamentada e, portanto, menos dispendiosa (LUPICA, 2015, p. 16).

No Brasil, apesar da licença paternidade existir desde 1967, a mesma permaneceu imutável com um dia de anuência, mesmo com as transformações sociais que ocorreram ao longo de 49 anos, só sendo modificada, em 2016. Neste tempo, apesar da Constituição de 1988 sinalizar a necessidade de mudança da licença paternidade, a mesma 
ainda não foi regulamentada, quando diversos textos legislativos que tinham como finalidade normatizar a mesma eram (e ainda são) preteridos pelo Congresso.

Assim, podemos constatar que a possibilidade de uma licença parental no Brasil ainda está longe da realidade. Mesmo durante os governos socialistas no país, a medida sequer era debatida de forma pública e séria pela sociedade, tendo como único avanço neste período a aprovação da Lei da Empresa Cidadã, que, entretanto, não contempla universalmente os trabalhadores brasileiros. Assim, no atual contexto de conservadorismo, a probabilidade de uma licença parental ser instituída torna-se quase nula, já que diversos segmentos que veem na divisão sexual do trabalho uma forma de manutenção dos privilégios de determinados grupos são representados no congresso e mesmo no executivo. A garantia de condições equitativas para o cuidado com os filhos nos primeiros meses de vida, apesar de ser uma bandeira defendida por alguns grupos de pais, ainda não é uma reivindicação dos homens em geral, que por se beneficiarem desta estrutura, acabam por sequer visualizarem a necessidade de tal política.

A adoção da licença parental poderia surtir efeitos benéficos para os próprios homens, garantindo a possibilidade do estreitamento dos laços com os filhos, além de causar o impacto, nas gerações futuras, de maior igualdade de gênero. Com paternidades mais ativas, masculinidades menos nocivas, crianças mais bem assistidas, mulheres menos sobrecarregadas. Desta forma, investir na construção de uma nova paternidade, mais participativa, é também investir em um caminho de maior equidade entre homens e mulheres, dado que não é possível erigir uma sociedade mais igualitária apenas empoderando mulheres sem (re)educar os homens.

\section{Referências}

ANDRADE, Luiza Lobato. Gênero, trabalho e bem-estar social na América Latina: um estudo das políticas de licenças maternidade, paternidade 
e parentais no Brasil, Chile e Uruguai. 2018. p. 127. Dissertação (Mestrado em Ciências Sociais) - Departamento de Estudos LatinoAmericanos, Universidade de Brasília, Brasília, 2018.

BESSE, Susan K. Modernizando a desigualdade: Reestruturação da ideologia de gênero no Brasil, 1914-1940. São Paulo: Editora USP, 1999.

BIROLI, Flávia. Gênero e desigualdades: os limites da democracia no Brasil. São paulo: Boitempo, 2018.

BRASIL. Constituição (1988). Constituição da República Federativa do Brasil. Brasília, DF: Senado Federal: Centro Gráfico, 1988

CONNELL, Raewyn. Gênero em termos reais. São Paulo: Versos, 2016.

DE OLIVEIRA, Pedro Paulo. A construção social da masculinidade. Editora UFMG, 2004.

FARIA, Carlos Aurelio Pimienta de. Entre marido e mulher, o estado mete a colher: reconfigurando a divisão do trabalho doméstico na Suécia. Red Revista Brasileira de Ciências Sociais, 2000.

HONNETH, Axel. Luta por reconhecimento: a gramática moral dos conflitos sociais. São Paulo: Editora 34, 2009.

LUPICA, Carina. Corresponsabilidad de los cuidados y autonomía económica de las mujeres: Lecciones aprendidas del Permiso Postnatal Parental en Chile. 2015.

MARTINS, Ana Paula Vosne. Políticas públicas para a maternidade e a infância no Brasil na primeira metade do século XX. In: História da saúde: olhares e veredas. 2010. p. 99-121.

MATOS, Ana Carla Harmatiuk; DE OLIVEIRA, Ligia Ziggiotti; DE NATIVIDADE, João Pedro Kostin Felipe. Licença parental como agenda para a igualdade de gênero: diálogos entre os modelos sueco e brasileiro. Revista da Faculdade de Direito UFPR, v. 61, n. 3, p. 345-363, 2016.

MELO, Cláudia Virgínia Brito. Proteção à maternidade e licença parental no mundo. Câmara dos Deputados: Brasília, 2019.

MOUFFE, Chantal. Democracia, cidadania e a questão do pluralismo. Política E Sociedade, v. 2, n. 3, p. 11-26, 2003. 
PINTO, Céli Regina J. Uma história do feminismo no Brasil. 1. ed. São Paulo: Editora Perseu Abramo, 2003.

RAMIRES, Vera Regina. O exercício da paternidade hoje. 1. ed. Editora Record, 1997.

REA, Marina. Benefícios à mãe trabalhadora: conquistas e recuos nas políticas públicas. In: BRUSCHINI, Cristina; UNBEHAUM, Sandra G. (Org.). Gênero, democracia e sociedade brasileira. São Paulo: Ed. 34, 2002. p. 391-402.

SANTANDER. Caderno de Indicadores. São Paulo: Banco Santander. 2019.

SCOTT, Joan. Gênero: uma categoria útil de análise histórica. 2012.

URUGUAY. Informe de investigación: Sensibilización para el uso del subsidio de medio horario por parte de los varones padres. Montevidéo: Grupo Pértiga, 2017. Disponível em: http:// www.sistemadecuidados.gub.uy/innovaportal/file/93257/1 / sensibilizacion-para-el-uso-del-subsidio-de-medio-horario-porparte.pdf Acesso em: 30 dez. 2018.

WALBY, Sylvia. Cidadania e transformações de gênero. In: TATAU, Godinho; SILVEIRA, Maria Lucia (Org.). Políticas públicas e igualdade de gênero. São Paulo: Coordenadoria Especial da Mulher, 2004. p. 169182.

WEBER, Max. A Ética Protestante e o Espírito do Capitalismo. São Paulo: Companhia das Letras, 2004. 